\title{
Interplay of hyporheic exchange and fine particle deposition in a riverbed
}

Guangqiu Jin ${ }^{1,2}$, Yilin Chen ${ }^{1,2}$, Hongwu Tang ${ }^{1,2, \#}$, Pei Zhang ${ }^{1,3}$, Ling Li $^{4}$, D. A. Barry

${ }^{1}$ State Key Laboratory of Hydrology-Water Resources and Hydraulic Engineering, Hohai University, Nanjing, China. Emails: jingq@hhu.edu.cn, hhucyl@hotmail.com, hwtang@hhu.edu.cn, peizhang.hhu@gmail.com

${ }^{2}$ Centre for Eco-Environmental Modelling, College of Water Conservancy and Hydropower Engineering, Hohai University, Nanjing, China

${ }^{3}$ School of Civil Engineering, University of Queensland, Queensland, Australia.

${ }^{4}$ School of Engineering, Westlake University, Hangzhou 310024, China. Email:

liling@westlake.edu.cn

${ }^{5}$ Laboratoire de technologie écologique (ECOL), Institut d'ingénierie de l'environnement (IIE), Faculté de l'environnement naturel, architectural et construit (ENAC), Ecole Polytechnique Fédérale de Lausanne (EPFL), Station 2, 1015 Lausanne, Switzerland. Email:

andrew.barry@epfl.ch 
Advances in Water Resources, In Press, April 2019 


\begin{abstract}
Hyporheic flow transports fine particles into the riverbed, which can lead to clogging of the bed and in turn affect hyporheic flow and exchange processes. Field measurements and numerical simulations show the formation of a low-permeability layer (LPL) near the bed surface due to fine particle clogging, and consequently reduction of exchange fluxes between the bed and river water. A characteristic porosity $\left(\varepsilon^{*}\right)$ and time scale were derived to quantify the clogging process and effects on transport. Both the exchange flux and mean solute residence time were found to follow a power law relationship with $\varepsilon^{*}$. For the normalised particle exchange flux, the exponent is close to unity, i.e., a linear relationship with $\varepsilon^{*}$. The results also showed significant effects of the fine particle concentration, pressure difference, sediment collision efficiency and fine particle diameter on the bed clogging. Large values of these parameters led to intensified clogging, with the formation of different types of LPL.
\end{abstract}

Key words: hyporheic zone, fine particle clogging, inlet flux, mean residence time, river eco-system, water quality 


\section{Introduction}

As overlying water flows over a riverbed with bedforms such as dunes or ripples, flowbedform interaction generates pressure gradients at the sediment-water interface (SWI) that drive water flow into and out of the bedforms (Thibodeaux \& Boyle, 1987). This circulating flow provides a mechanism for mass exchange between the river water and bed (Elliott \& Brooks, 1997a, b). The area where the active circulating flow and exchange takes place in the bed is called hyporheic zone (Krause et al., 2009), which is an active portion of the fluvial eco-environment (Cardenas, 2006; Harvey \& Fuller, 1998; Malcolm et al., 2002; Mermillod-Blondin et al., 2005).

Fine particles are abundant in natural rivers, including inorganic colloids such as clay particles as well as organic plant debris and microbes (Hedges et al., 1986; Ren \& Packman, 2004). During rainfall and flood events, soil erosion from the upper catchment produces a significant input of fine particles into the river system (Packman \& MacKay, 2003; Pimentel et al., 1995; Wolman, 1967). These fine particles can be chemically reactive, particularly due to their large specific surface areas. For instance, fine particles were found to facilitate the migration of heavy metal elements such as zinc, copper and lead into the riverbed (Karathanasis, 1999, 2000; Ren \& Packman, 2005).

As the fine particles move downward into the bed driven by hyporheic flow, they can be trapped by small pores (Drummond et al., 2014; Harvey et al., 2012; Karwan \& Saiers, 2012; Packman et al., 2000a, 2000b; Packman \& Brooks, 1995; Packman \& MacKay, 2003), i.e., particle filtration (McDowell-Boyer et al., 1986). This leads to a reduction of the porosity and permeability of the bed, resulting in reduction of water exchange across 
the sediment-water interface (SWI), as shown in column experiments and numerical stimulations (Baveye et al., 1998; Chen et al., 2010, 2009, 2008; Fox et al., 2018; Mays \& Hunt, 2005, 2007; O’Melia \& Ali, 1978; Reddi et al., 2005; Rehg et al., 2005; Tosco \& Sethi, 2010; Zheng et al., 2014). Field experiments also show that river turbidity could enhance fine particle clogging in the river bank (Pholkern et al., 2015). This can further affect biological processes in the hyporheic zone as material and energy transfer associated with water exchange becomes constrained (Findlay, 1995).

Even with (initially) uniform bedforms, hyporheic flow is spatially variable, which is expected to affect the deposition of fine particles in the bed, eventually resulting in heterogeneity of the riverbed's porosity and permeability. However, previous research typically assumed the bed to be homogenous (Cardenas \& Wilson, 2007a; Elliott \& Brooks, 1997b; Jin et al., 2010). A few studies on heterogeneous riverbeds showed that heterogeneity affected significantly vertical exchange between surface water and groundwater (Fox et al., 2016) as well as exchange rates and mean residence times of solutes in the hyporheic zone (Pryshlak et al., 2015). However, the bulk heterogeneity was found to have little impact on the reactive transport behaviour and bulk reaction rates of solutes in the streambed (Bardini et al., 2013). At present, the potential effects of particle trapping in bedforms are not well understood. For example, the hydraulic conductivity of the bed under the influence of particle trapping would change. However, it is unclear what the patterns of these changes are, i.e., how the hydraulic conductivity variations affect the mean residence time and transport paths of solutes in the hyporheic zone. 
By combining field measurements and numerical stimulations with a simple analytical model, we aim to address the following questions: (1) How does particle clogging affect the porosity and permeability of the riverbed? (2) How does particle clogging affect hyporheic exchange, particularly the flux and solute residence time? Finally, (3) what factors play a role in modulating the particle clogging effect? A field experiment was conducted in the Huaihe River (China) during a flood event in 2016 with the aim of exploring possible effects of fine particle deposition on intrinsic properties of the beds under real conditions. Motivated by the field observations, a numerical model was then developed to stimulate the process of fine particle transport and deposition coupled with hyporheic flow. A modified Kozeny-Carman equation (Xu \& Yu, 2008) was adopted to describe the relationship between porosity and permeability (hydraulic conductivity). An analytical model was also developed to describe the clogging process and resulting effects on the permeability near the bed surface. The numerical simulation results were analysed in combination with the analytical solution to address the above questions.

\section{Approach and methodology}

\subsection{Field investigation}

The field experiment was conducted near $\mathrm{Wu}$ Jia $\mathrm{Du}$ at the Huaihe River in eastern China (Fig. 1a) during a modest flood event to examine fine particle transport and clogging in the bed of a natural river under real conditions. Prior to the flood event, sand was dredged from the bed and sieved through a $0.250 \mathrm{~mm}$ sieve and $0.355 \mathrm{~mm}$ sieve. The remaining sand (mainly $0.3 \mathrm{~mm}$ ) was then deposited on the floodplain near the deep channel to form a $1.4 \mathrm{~m}$ long and $0.147 \mathrm{~m}$ high sand dune (Fig. 1b-d) for simulating a bedform. The bulk 
properties of the sand dune, including bulk density and hydraulic conductivity, were measured (Table 1). During the flood event, the dune was inundated by river water, and hyporheic exchange occurred between the dune and overlying water.

The experiment lasted for 7 days. The mean river flow velocity (measured by propeller current meter, LS1206B, Qingdao Junyuan Environment Equipment Co. Ltd.), water depth and fine particle concentration during the experiment are shown in Fig. 2. Mean flow velocity and water depth were measured at one meter upstream of the sand dune and found to be relatively stable with a fine particle concentration around $0.5 \mathrm{~kg} / \mathrm{m}^{3}$ for the majority of the experiment except the beginning and end of the flood event. The duration of this period is about 87 hours as highlighted in Fig. 2. During the period of the experiment, the flow direction was predominantly from the stoss side to the lee side of the dune as measured by propeller current meter. Little bed movement was observed at the beginning and the sand dune remained largely unchanged.

As the flood receded, the sand dune re-emerged. The middle of the dune was sampled across two vertical layers, with three samples taken from each layer. At the upper layer, samples were collected near the surface, and at the deeper layer samples were extracted 9 $\mathrm{cm}$ below the dune surface. Each sample was collected by a cutting ring of $61.6 \mathrm{~mm}$ in diameter and $40.0 \mathrm{~mm}$ in height. If fine particle trapping occurs in the bed, the bulk density of the sediment is expected to increase. To examine this effect, the bulk densities of the samples were measured following the method GB/T50123-1999 (Professional Standards Compilation Group of People's Republic of China, 1999). The samples were then passed through a $0.1 \mathrm{~mm}$ sieve to separate large $(>0.1 \mathrm{~mm})$ and small particles $(<$ $0.1 \mathrm{~mm}$ ). Since the sand dune was made of particles of sizes in excess of $0.1 \mathrm{~mm}$, small 
particles found via sieving are mainly from the infiltrating river water. Note that although sediment samples taken from the dune would include fine particles in the pore water, the amount was negligible because of the low sediment concentrations in the river water (approximately $0.5 \mathrm{~kg} / \mathrm{m}^{3}$ ). The particle size distribution of the sieved small particle samples was determined with a Malvern laser particle size analyser. Samples of overlying river water were also collected during the flood for measurement of the particle concentration and size distribution of the suspended load. These measurements allowed for determination of the mass distribution of clogged particles in the shallow and deep areas of the bedform as well as the size distribution of the trapped particles in comparison to the suspended fine particles in the river water.

If fine particles are too large to go through at the pore throat in the shallow area of the bed, bridging will occur and prevent subsequent migration of fine particles into deeper regions of the streambed. The critical condition separating bridging and unimpeded static percolation is given by $d_{\mathrm{c}}{ }^{*} / d_{85}=3$, where $d_{\mathrm{c}}{ }^{*}$ is the controlling constriction size, $\cong 0.25 d_{5}$ with $d_{x}$ being the $x^{\text {th }}$ percentile of the particle diameter distribution (Gibson et al, 2010; Wharton el at., 2017). If $d_{\mathrm{c}}{ }^{*} / d_{85}>3$, no bridging occurs. The $d_{\mathrm{c}}{ }^{*} / d_{85}$ was $4.26\left(d_{85}=17\right.$ $\mu \mathrm{m}$ and $d_{5}=0.29 \mathrm{~mm}$ ), suggesting that bridging did not occur. Thus, the bridging process was not considered in the mathematical model for simulating the fine particle transport in the riverbed.

\subsection{Conceptual and mathematical model}

Along with the field observation of fine particle transport and trapping in the sand dune (§3), a mathematical model was developed to simulate the particle transport and trapping 
in the bed with consideration of the feedback of particle trapping on the flow process through changes of the bed properties. The model was based on a 2D vertical section of the bed in the longitudinal (flow) direction, with boundary conditions given in Fig. 3.

The river water flow above the bed interacts with the bedforms and generates hydraulic head gradients that drive hyporheic flow and exchange. A sequential coupling approach was applied to simulate the river water flow, and pore water flow and particle transport in the bed. First, the river water flow was simulated to determine the pressure distribution at the sediment-water interface (SWI). Then, the pore water flow in the bed, driven by the interfacial pressure variations, was simulated. Finally, particle transport was simulated based on the pore water flow field. This approach is similar to that of Cardenas and Wilson (2007b) and Jin et al. (2010).

The overlying water flow equations were solved using FLUENT (ANSYS Inc., Canonsburg, PA, USA; www.ansys.com), following the approach of Jin et al. (2010), as shown in Fig. 3. COMSOL Multiphysics (COMSOL, Inc., Burlington, MA, USA; see www.comsol.com) was used to simulate pore water flow and fine particle transport in the riverbed. The saturated pore water flow is described by (Bear, 1975),

$$
\frac{\partial}{\partial t}(\rho \varepsilon)+\nabla \cdot(\rho \boldsymbol{U})=0
$$

where $t$ is time, $\rho$ is fluid density, $\varepsilon$ is porosity and $\boldsymbol{U}$ is the Darcy flow velocity,

$$
\boldsymbol{U}=-\frac{K}{\rho g} \nabla(P+\rho g z)
$$


Above, $K$ is the hydraulic conductivity, $P$ is the pore-water pressure, $g$ is the magnitude of gravitational acceleration and $z$ is the vertical coordinate.

As mentioned, the pressure distribution at the SWI provided by the overlying water flow model was used to determine the top, pressure-prescribed boundary of the bed domain. The lateral (vertical) boundaries were set as periodic velocity and pressure boundaries with an imposed pressure/head drop (Cardenas \& Wilson, 2007a). The bottom boundary was set as a zero-flux boundary.

Fine particle transport in the bed was modelled using the mass transport equation, i.e.,

$$
\frac{\partial(\varepsilon C)}{\partial t}+\nabla \cdot\left(-\varepsilon D \nabla C-v_{p} \varepsilon C\right)+\frac{\partial S}{\partial t}=0
$$

In Eq. 3, $C$ is the fine particle concentration in the pore water; $S$ is the mass of retained particles per unit volume of porous medium, $v_{p}$ is the fine particle velocity vector and $\boldsymbol{D}$ is the 2D dispersion coefficient tensor. The fine particle velocity was calculated as $\boldsymbol{v}_{p}=\boldsymbol{u}$ $+\boldsymbol{v}_{s}$ (Packman et al., 2000), where $\boldsymbol{u}$ is the pore water flow velocity and $\boldsymbol{v}_{s}$ is the particle settling velocity calculated according to Stokes' law (Hunter, 1986). The second term on the left-hand side of Eq. 3 describes the net transport flux due to particle hydrodynamic dispersion, and particle migration due to pore water flow and particle settling. The third term represents fine particle deposition in the bed due to filtration. Following Ryan and Elimelech (1996), particle filtration was modelled using:

$$
\frac{\partial S}{\partial t}=k_{a t t} \varepsilon C
$$


where $k_{\text {att }}$ is the particle attachment coefficient, which quantifies the removal rate of fine particles due to filtration. The attachment coefficient was computed using (Bradford et al., 2003; Yao et al., 1971),

$$
k_{a t t}=\frac{3(1-\bar{\varepsilon})}{2 d} \alpha \eta u_{\mathrm{c}}
$$

where $d$ is the mean grain diameter of riverbed sediments; $\bar{\varepsilon}$ is the average porosity of the shallow bed layer, i.e., the top one third of the bed, where particle deposition mainly occurs (Packman \& MacKay, 2003; Rehg et al., 2005); and $u_{c}=K h_{m} /(L \bar{\varepsilon})$ is a characteristic pore water velocity (Jin et al., 2010) with $h_{m}$ being the amplitude of hydraulic head variations along the SWI and $L$ being the length of a single bedform. Note that $u_{\mathrm{c}}$ is taken as a constant spatially but changes over time. The distribution of pressure differences remains unchanged during the simulation; however local porosity and hence averaged porosity $(\bar{\varepsilon})$ and hydraulic conductivity $(K)$ decrease due to fine particle deposition. At each time step, new characteristic pore-water velocity is obtained based on updated values of $\bar{\varepsilon}$ and $K$. The particle collision efficiency, $\alpha$, is usually determined by a column penetration experiment (Auset \& Keller, 2006; Bradford et al., 2003; Karwan \& Saiers, 2012; Liu et al., 1995; Ren et al., 2000, 2001). The collector efficiency, $\eta$, was calculated using (Rajagopalan and Tien, 1976),

$$
\eta=4 A_{s}^{1 / 3}\left(\frac{3 \pi \mu}{B_{z} T} d_{p} d \bar{\varepsilon} u_{c}\right)^{-2 / 3}+A_{s}\left(\frac{4 H}{9 \pi \mu}\right)^{1 / 8} \frac{d_{p}^{13 / 8}}{\left(\bar{\varepsilon} u_{c}\right)^{1 / 8} d^{15 / 8}}+0.00338 A_{s}\left[\frac{\left(\rho_{p}-\rho\right) g}{18 \mu}\right]^{1.2} \frac{d_{p}^{2} d^{0.4}}{\left(\bar{\varepsilon} u_{c}\right)^{1.2}}
$$


where $d_{p}$ is the fine particle diameter; $\mu$ is the dynamic viscosity of water; $\rho_{p}$ is the density of the particles; $H$ is the Hamaker constant $\left(10^{-20} \mathrm{~J}\right) ; B_{z}$ is Boltzmann's constant $\left(1.38 \times 10^{-23} \mathrm{~kg} \mathrm{~m}^{2} \mathrm{~s}^{-2} \mathrm{~K}^{-1}\right) ; T$ is the temperature $(\mathrm{K})$; and $A_{s}$ is the Happel correction factor,

$$
A_{s}=2\left[1-(1-\bar{\varepsilon})^{5 / 3}\right] /\left[2-3(1-\bar{\varepsilon})^{1 / 3}+3(1-\bar{\varepsilon})^{5 / 3}-2(1-\bar{\varepsilon})^{2}\right]
$$

The clogging effect due to fine particle trapping leads to reduction of porosity $(\varepsilon)$, i.e.,

$$
\varepsilon=\varepsilon_{0}-\frac{S}{\rho_{\mathrm{p}}}
$$

where $\varepsilon_{0}$ is the initial porosity of the porous medium. The mean bed sediment diameter is assumed not to be affected significantly by fine particle clogging, in which case the single-collector efficiency equations (Eqs. 5 and 6) still apply for computing $k_{a t t}$ and $\eta$ using temporally varying average porosity. Both parameters are constant spatially but vary over time.

A modified form of the Kozeny-Carman equation was used to determine the consequent change in the permeability, $\kappa(\mathrm{Xu} \& \mathrm{Yu}, 2008)$,

$$
\kappa=\frac{\varepsilon^{3}}{c(1-\varepsilon)^{2} A^{2}}
$$

where $c$ and $A$ are constants related to the intrinsic properties of the porous medium. We hypothesised that these values do not change significantly due to fine particle clogging. Changes in hydraulic conductivity (proportional to permeability) then follow: 


$$
K=K_{0} \frac{\left(1-\varepsilon_{0}\right)^{2} \varepsilon^{3}}{\varepsilon_{0}^{3}(1-\varepsilon)^{2}}
$$

where $K_{0}$ is the initial hydraulic conductivity. This equation is consistent with the previous finding of a power law relationship between hydraulic conductivity and porosity in the fine particle clogging process (Chen el al., 2010).

The boundary conditions for the fine particle transport were set as follows (Fig. 3): (1) on the lateral boundaries of the domain, periodic conditions were imposed for both the concentration and the concentration gradient; (2) on the bottom of the domain, a no-flux condition was applied, giving a zero concentration gradient since the local vertical flow and advective flux are zero on this boundary; and (3) along the SWI, the boundary condition was:

$$
\begin{cases}C=C_{c} & \mathbf{n} \cdot \mathbf{u} \geq 0 \\ \frac{\partial C}{\partial n}=0 & \mathbf{n} \cdot \mathbf{u}<0\end{cases}
$$

where $\mathbf{n}$ is the unit vector normal to the interface (pointing inward), and $C_{\mathrm{c}}$ is the fine particle influx concentration along the SWI:

$$
\begin{cases}C_{c}=C_{0} & \varepsilon>\varepsilon_{\min } \\ C_{c}=0 & \varepsilon=\varepsilon_{\min }\end{cases}
$$

In Eq. 12, $C_{0}$ is the fine particle concentration in the overlying water and $\varepsilon_{\min }$ is the minimum possible porosity. If the diameters of fine particles are equal and follow a hexagonally closely-packed array, $\varepsilon_{\min }$ is given by $0.2596 \varepsilon_{0}$ (Graton \& Fraser, 1935). 
When $\varepsilon$ is reduced to $\varepsilon_{\min }$, the medium is assumed to be "fully" clogged. This occurs at the bed surface and subsequently no further fine particle transfer to the bed is possible, though water still flows through.

\subsection{Model simulations}

Motived by the field observations, a series of simulations were conducted with model parameter values listed in Table 3 to examine fine particle transport and clogging in the hyporheic zone. These simulations focussed on the case with periodic bedforms, as considered in previous studies (Karwan \& Saiers, 2012; Packman et al., 2000a, 2000b).

The properties of bed sediments adopted in the simulations correspond with those of Huaihe River sediments. The fine particle diameters range from 1 to $10 \mu \mathrm{m}$, covering the majority of fine particles detected in the field experiment. The sediment collision efficiency, $\alpha$, is affected by various factors, including $\mathrm{pH}$ and pore water ionic strength. Although there are theories for predicting the value of $\alpha$, many previous studies treated it as a fitting parameter based on model calibration against data from column experiments (Bradford et al., 2003; Karwan \& Saiers, 2012; Ren et al., 2000).

A base case simulation was first conducted to examine the particle clogging effect with the particle concentration, pressure difference, particle diameter and sediment collision efficiency set to $0.5 \mathrm{~kg} / \mathrm{m}^{3}, 4.75 \times 10^{-4} \mathrm{~m}, 1 \mu \mathrm{m}$ and 0.04 , respectively. The values of these four model parameters were then varied to explore how changes in theses parameters influence particle clogging and hyporheic exchange. The range of sediment collision efficiencies is within those considered in the previous studies (Bradford et al., 
2003; Karwan and Saiers, 2012; Ren et al., 2000). Numerical simulation results were also used to calibrate an analytical clogging model described below.

\subsection{Analytical clogging model}

Combining Eqs. 4 and 8 leads to an expression for describing the changes of porosity $\varepsilon$ in the hyporheic zone due to fine particle clogging:

$$
-\rho_{p} \frac{\partial \varepsilon}{\partial t}=\frac{k_{a t t}}{\alpha h_{m}} \varepsilon \alpha h_{m} C
$$

According to Eqs. 5, 6 and 10, $k_{\text {att }} /\left(\alpha h_{m}\right)$ can be approximated as a power function of porosity, $\varepsilon$, as shown in Fig. 7,

$$
\frac{k_{a t t}}{\alpha h_{m}} \cong m \varepsilon^{-n}
$$

where $m$ is function of $d_{\mathrm{p}}$ and $h_{\mathrm{m}}\left(m=k d_{p}^{2} h_{m}^{-0.87}, k=4.43 \times 10^{6}\right.$, the values of these parameters were based on curve-fitting). The value of $n$ was found to be approximately 4.3 based on curve-fitting. Equation 13 can be applied to the SWI with $C$ set to $C_{0}$ and integrated to give a solution for local porosity prior to reaching the minimum value, i.e.,

$$
\varepsilon^{*}=\left(\varepsilon_{0}^{n}-\frac{n}{\rho_{p}} m \alpha h_{m} C_{0} t\right)^{\frac{1}{n}}
$$

Based on Eq. 14, the time taken for the SWI to become clogged (termed clogging time hereafter) is: 


$$
t_{\mathrm{c}}=\frac{\rho_{p}}{n m \alpha h_{m} C_{0}}\left(\varepsilon_{0}^{n}-\varepsilon_{\min }^{n}\right)
$$

As $m=k d_{p}^{2} h_{m}^{-0.87}$, Eq. 15 is rewritten as:

$$
t_{\mathrm{c}}=\frac{\rho_{p}}{n k d_{p}^{2} \alpha h_{m}^{0.13} C_{0}}\left(\varepsilon_{0}^{n}-\varepsilon_{\mathrm{min}}^{n}\right)
$$

\section{Results and Discussion}

\subsection{Field observations and simulation}

Field measurements show that while the bulk densities of sediment samples collected from the deep layer differed little from initial values (prior to the flood), the bulk densities of samples taken near the dune surface increased from 1.70 to over $1.81 \mathrm{~g} / \mathrm{cm}^{3}$ (i.e., 6.40-8.38\%, Table 2). Few fine particles were found in the samples from the deep layer. In contrast, a considerable amount of fine particles were extracted from the samples collected near the dune surface. The size distribution of these fine particles was similar to that of suspended sediments in the overlying water, for instance both with $d_{50}$ around $10 \mu \mathrm{m}$ (Fig. 4). These results suggested that fine particles from the overlying water were transported into the sand dune by the hyporheic flow and that fine particles were trapped near the dune surface, consistent with the numerical simulation results shown below.

\subsection{Numerical simulations}

Simulations were conducted to examine fine particle deposition and clogging, as well as changes in hyporheic flow. Variations due to different fine particle sizes, sediment 
collision efficiencies, particle concentrations and pressure difference were quantified.

The simulations used triangular bedforms, as commonly considered in previous studies of hyporheic flow (Cardenas \& Wilson, 2007a, b; Karwan \& Saiers, 2012), with values of $\alpha$ and $d_{p}$ varying, respectively, from 0.04 to 0.6 and from 1 to $10 \mu \mathrm{m}$. Values of $C_{0}$ and $h_{m}$ were varied from 0.5 to $16 \mathrm{~kg} / \mathrm{m}^{3}$ and from $1.11 \times 10^{-4}$ to $6.44 \times 10^{-4} \mathrm{~m}$, respectively.

\section{Clogging characteristics and effects - Base case}

The simulation results show the development of a thin sediment layer with fine particles trapped below the bed surface within the inflow zone, localized near the entrance of each circulating path (Fig. 5a). This numerical result is consistent with the field observation presented above and findings of previous studies, which showed that fine particle movement is different from solute transport. Fine particle clogging is localised, with trapped fine particles distributed within a shallow area along the sediment-water interface (Fox et al., 2018; Drummond et al., 2014; Harvey et al., 2012; Chen el al., 2010; Rehg et al., 2005). With time, this layer expanded along the (local) flow path. Fine particle trapping reduced the porosity, which in turn intensified particle trapping as indicated by

Eq. 13. The concentrations of trapped particles $(S)$ at the bed surface eventually reached a maximum $\left(S_{\max }\right)$ corresponding to the minimum porosity $\left(\varepsilon_{\min }\right)$. Afterwards, no further transfer of fine particles into the bed took place (Eq. 12). The vertical profiles of trapped particle concentrations consistently show the positive feedback of clogging on fine particle deposition, as manifested by the development of the high concentration layer close to the bed surface (Fig. 6). 
As trapped particles occupy pore space and reduce porosity, the medium's permeability in the surface layer decreases. The formation of the low-permeability layer (LPL) weakens hyporheic flow and alters the pore-water pressure distribution and flow patterns (Fig. 5b). Pore-water pressure reduced rapidly in the low permeability layer, which is consistent with the experiment conducted by Fetzer et al. (2017). A major impact is the reduction of the extent of the hyporheic zone (also called interfacial exchange zone, IEZ) (Cardenas \& Wilson, 2006). The thickness of the IEZ decreased as its lower bound (the hydraulic divide separating the IEZ and regional flow zone) moved upward until the particle trapping ceased (Fig. 5b).

The overall exchange between the river and the bed was also affected. Both the total water influx $\left(q_{w}\right)$ and relative fine particle influx $\left(q^{*} p\right)$ (fine particle influx normalized by the initial fine particle influx) across the bed surface decreased over time, reaching a minimum and zero, respectively, as the bed (surface) became "fully" clogged (Fig. 8) and an equilibrium state was established. The existence of this relative equilibrium state was also evinced by Fetzer et al's experiments (Fetzer et al., 2017). In the Fetzer's experiment, after fine particle entered the column for a period of time, the rate of hydraulic conductivity reduction decreased drastically, which suggests a steady state was reached (Fetzer et al., 2017). However, the hydraulic conductivity did not cease to decrease as numerical model suggested. The continuing slow decrease of hydraulic conductivity may be the result of further migration of fine particles into deeper regions, since the experiments measured the whole column hydraulic conductivity. The clogging time $\left(t_{c, n}\right)$ was $5.04 \times 10^{4} \mathrm{~h}$ for the base case. The averaged porosity $\left(\varepsilon_{a}\right)$ on the bed surface across the inflow zone was also determined. The results show a decreasing trend until reaching 
$\varepsilon_{\text {min }}$, similar to the trends of $q_{w}$ and $q^{*}{ }_{p}$ (Fig. 8). A power-law relationship with $\varepsilon_{a}$ was found for $q_{w}$, whereas $q_{p}^{*}$ exhibited a linear relationship with $\varepsilon_{a}$ as reported by Fox et al. (2018) (Fig. 8). We determined the length where the fine particle entranced the bed surface. A dimensionless entrance length $L_{p}{ }^{*}$ was calculated, which equalled the entrance length of fine particles divided by the length of the SWI. We found that $L_{p}{ }^{*}$ increased over time until reaching a maximum value, which implied that some initially outflux zone would become influx zone. This is supported by Fox et al.'s findings for experiments with neutral and losing conditions. Fine particle depositing and clogging inflow zone of the bed would divert inflowing water laterally and shift inflow to other areas of the bed (Fox et al., 2018), which could be the result of fine particle clogging. Tonina et al. (2016) had shown that heterogeneity induced by the change of hydraulic conductivity could switch certain upwelling zone of hyporheic zone to downwelling zone. With the initial increase of $L_{p}{ }^{*}, q^{*}$ decreased relatively slowly compared with the rapid decline when $L_{p}{ }^{*}$ reached the maximum.

The area $\left(A_{L P L}\right)$ and thickness $\left(d_{c}\right)$ of the LPL were found to follow a hyperbolic function type relationship $(a \cosh (x)+b)$ with $\varepsilon_{a}$ (Figs. 8). Note that $A_{L P L}$ was calculated as the area of riverbed where the local permeability was reduced to half of the initial permeability (Fig. 5b) while $d_{c}$ was estimated by dividing $A_{L P L}$ by the bedform length given that the LPL spanned almost the whole bedform. We also computed the averaged fluid residence time $\left(t_{r}\right)$ in the IEZ to explore variations of the overall flow in the hyporheic zone (Cardenas \& Wilson, 2006), i.e.,

$$
t_{r}=\frac{\overline{\varepsilon_{I E Z}} A_{I E Z}}{q_{w}}
$$


where $\overline{\varepsilon_{I E Z}}$ and $A_{I E Z}$ are the average porosity and area of the hyporheic zone, respectively. Again, $t_{r}$ was found to be related to a power of $\varepsilon_{a}$ (Figs. 8). These results suggest that $\varepsilon_{a}$ is a key characteristic variable of the hyporheic zone as affected by fine particle clogging.

Analytical predictions of $\varepsilon_{a}\left(\varepsilon^{*}\right)$ and $t_{c}$ (base case)

The analytical model provides predictions for the temporally varying porosity $\left(\varepsilon^{*}\right)$ at the interface, as simulated by the numerical model $\left(\varepsilon_{a}\right)$. To compare the analytical solution (Eqs. 14 and 15) with the numerical results $\left(\varepsilon_{a}\right.$ and $\left.t_{c}\right)$, we first determined the coefficients $m$ and $n$ by approximating the relationship between $k_{a t t} / \alpha h_{m}$ and $\varepsilon$ based on Eq. $13 \mathrm{~b}$ for different values of $h_{m}$. As shown in Fig. 8, the approximation is reasonably good, with relatively large regression coefficient values obtained for the fitting $\left(R^{2}>\right.$ $0.95)$. Note that the values of $m$ varied considerably with $d_{p}$ while $n$ varied little $(\sim 4.3)$. With these values, Eq. 14 predicted how the interface porosity varied with time. Both $\varepsilon_{a}$ and $\varepsilon^{*}$ decreased over time (Fig. 9). However, $\varepsilon^{*}$ underestimated the decrease of porosity as simulated by the model $\left(\varepsilon_{a}\right)$. The discrepancy between the analytical solution and numerical model result is due to the approximation of the power law relationship between the $k_{a t t} / \alpha h_{m}$ and $\varepsilon$ adopted in the analytical model, which is not accurate particularly for the base case. Using in the numerical model the value of $k_{a t t} / \alpha h_{m}$ given by the same power-law approximation, the simulated $\varepsilon_{a}$ agrees well with $\varepsilon^{*}$ predicted by the analytical solution (red square in Fig. 9).

The analytical model, based on the interface condition alone, does not consider the effect of flow and particle transport and deposition below the interface, nor the lateral 
expansion of the entrance length at the bed surface. Although it underpredicts the clogging process, the analytical solution provides parametric relations that allow examination of the roles of key physical parameters in the clogging process, in particular, the fine particle concentration, pressure difference, fine particle size and sediment collision efficiency as discussed below.

Effects of fine particle concentration $\left(C_{0}\right)$, pressure difference $\left(h_{m}\right)$, fine particle size $\left(d_{p}\right)$ and sediment collision efficiency $(\alpha)$

Simulations with different values of $C_{0}, h_{m}, d_{p}$ and $\alpha$ show similar clogging effects and characteristics to those found in the base case. In particular, $\varepsilon_{a}$ characterises the dynamics of the hyporheic zone in the simulation with respect to changes in the shallow layer porosity, and feedback on the flow and particle deposition. The results for all cases are included in the Supplementary Materials (Figs. S1, S2, S3 and S4).

The following trends can be identified from the results: (1) Larger fine particle concentrations accelerate the clogging process (Fig. 8) but do not change overall clogging pattern (Fig. S1); (2) Larger pressure differences increase the intrusion of fine particles, thus leading to the formation of a more extensive LPL near the bed surface (Fig. S2); (3) Larger fine particle collision efficiencies intensify the clogging process and lead to the formation of thinner LPLs near the bed surface (Fig. S3); (4) Larger fine particle sizes also intensify the clogging process; however, the LPLs expanded across the bedform (both lateral and vertical) due to increased particle settling velocities (Fig. S4); and (5) $\varepsilon_{a}$ was also found to be the key characteristic variable that maintains a power law relationship with water exchange flux and solute residence time, a linear relationship with 
relative particle exchange flux and a hyperbolic function relationship with LPL thickness (Fig. 8).

The results also show that: (1) the exponents of the power function of $\varepsilon_{a}$ versus $q_{w}$ and $t_{r}$ remained unchanged except for the cases with different sediment collision efficiencies. When the sediment collision efficiency is larger, LPL is restrained to the sediment-water interface, which limits its ability to resist the exchange flux at the surface (Fig. S4); (2) fine particles started to intrude on the lee side of the bed, when the pressure difference at the surface became low. This is because the fine particle's settling effect dominates over the upwelling associated with the hyporheic outflow.

Here, we focus on comparing the analytical predictions of $\varepsilon^{*}$ and $t_{c}$ with the simulation results $\left(\varepsilon_{a}\right.$ and $\left.t_{c, n}\right)$ to explore the roles of $C_{0}, h_{m}, d_{p}$ and $\alpha$ in affecting the fine particle clogging and transport in the riverbed. Figure 10 shows the comparison of $t_{c}$ for different $C_{0}, h_{m}, d_{p}$ and $\alpha$. In each case, the analytical solution was first applied directly with model parameter values determined based on the simulated condition, i.e., the values of $m$ and $n$ derived using the fitting method described in the above section. Second, the $t_{c} \propto C_{0}^{-1}, t_{c} \propto h_{m}^{-0.13}, t_{c} \propto d_{p}^{-2}$ and $t_{c} \propto \alpha^{-1}$ relationships given by the analytical solution were used to fit the simulation results. The second approach led to a slightly improved match between the analytical and numerical results. Overall, the analytical predictions compared reasonably well with the numerical results. The comparisons between $\varepsilon^{*}$ and $\varepsilon_{a}$ for different particle sizes are shown in Fig, 11. In these cases, the power function could accurately predict the relationship between $k_{a t t} / \alpha h_{m}$ and $\varepsilon$, hence, the analytical predictions agreed well with the numerical results. 


\section{Concluding remarks}

Combining results from a field experiment, numerical simulations and an approximate analytical solution, we estimated clogging of the riverbed near the sediment-water interface by fine particles that are transported from overlying river water due to hyporheic flow. The clogging leads to formation of a thin, low-permeability layer near the interface, which in turn reduces the hyporheic flow and exchange fluxes. The analytical solution describes changes of porosity near the interface and time for the bed to become "fully" clogged. Both quantities are affected by various physical parameters as described by the analytical solution. Moreover, changes of hyporheic exchange fluxes, solute residence time, relative particle exchange fluxes and low permeability layer thickness are related to temporal variations of porosity near the interface by power-law, linear and hyperbolic functions, respectively. Using these relations together with the analytical solution, we can demonstrate the clogging process and assess the resulting effects on the bed properties and hyporheic exchange.

The field experiment carried out in the present study provided evidence for fine particle transport and trapping in the riverbed. However, the retention of fine particles in bed sediments is of great complexity in the natural river system. For example, turn-over of streambed (Rehg et al., 2005), influence of ambient flow (Fox et al., 2018) and change of bed condition from full water saturation to partial saturation would complicate the transport and trapping of fine particles in the bed in ways not considered here. The clogging time, $t_{c}$, as predicted by the analytical model based on steady-state flow conditions, is affected by various factors, such as fine particle concentration, pressure variations at sediment water interface, particle diameter and sediment collision efficiency. 
Under conditions of large particle diameter and high sediment collision efficiency, the equilibrium state of fine particle clogging in the bed may be reached rather quickly. For instance, if the fine particle concentration is $16 \mathrm{~kg} / \mathrm{m}^{3}$, for a particle diameter of $10 \mu \mathrm{m}$ and sediment collision efficiency of 0.6 , clogging would take around $1 \mathrm{~h}$. Over such time periods, steady state or quasi-steady state flows may occur in some natural rivers. Thus, we suggest that our analytical model based on steady state flow conditions provides a methodology and with validation has the potential for predicting the time scale of fine particle clogging of natural riverbeds, especially when the fine particle concentration, fine particle diameter and sediment collision efficiency are large, and the flow rate of river is steady. In Fox et al.'s experiment, clogging times ranged from $20 \mathrm{~h}$ to $100 \mathrm{~h}$ (Fox et al., 2018). Although, we do not know their exact values of fine particle diameter and sediment collision efficiency, estimations can be made. The value of sediment collision efficiency could be approximated as 0.42, following Karwan and Saiers (2012) who used a similar sediment composition in their experiments, and the diameter of fine particles between $2 \sim 7 \mu \mathrm{m}$, based on other experiments that also used kaolinite as fine particles for studying bed clogging (Jin et al., 2019; Rehg et al., 2005). Then, from the analytical solution we predict a clogging time ranging from $6 \sim 75 \mathrm{~h}$, which is on the same time scale as given by experimental measurements. Nevertheless, further experiments under wellcontrolled laboratory conditions should be carried out to examine the particle clogging process and effects, in parallel to model simulations. In addition to particle concentration, pressure difference, fine particle size and particle collision efficiency as examined here, future investigations should explore the influences of other parameters, including the bed sediment size, bed permeability and different bedform shapes. The influence of bottom 
boundary conditions should also be further explored, for fluxes across the bottom boundary associated with regional scale flow of gaining or losing rivers can influence the migration of fine particles in the bed (Fox et al., 2018).

\section{Acknowledgments}

This research was supported by the Natural Science Foundation of China (51421006, 51679065), the Fundamental Research Funds for the Central Universities (2018B616X14), Priority Academic Program Development of Jiangsu Higher Education Institutions (YS11001), Basic Research Programs (Natural Science Foundation) of Jiangsu Province (BK20171436) and Postgraduate Research \& Practice Innovation Program of Jiangsu Province (KYCX18_0601). We also thank two anonymous reviewers for providing constructive comments that greatly improved this paper. Data used in the analysis presented in the paper can be obtained by sending a request to the corresponding author (hwtang@hhu.edu.cn). 


\section{References}

Auset, M., Keller, A.A., 2006. Pore-scale visualization of colloid straining and filtration in saturated porous media using micromodels. Water Resour. Res. 42, 401-414. doi:10.1029/2005WR004639

Bardini, L., Boano, F., Cardenas, M.B., Sawyer, A.H., Revelli, R., Ridolfi, L., 2013. Small-scale permeability heterogeneity has negligible effects on nutrient cycling in streambeds. Geophys. Res. Lett. 40, 1118-1122. doi:10.1002/grl.50224

Baveye, P., Vandevivere, P., Hoyle, B.L., DeLeo, P.C., de Lozada, D.S., 1998. Environmental impact and mechanisms of the biological clogging of saturated soils and aquifer materials. Crit. Rev. Environ. Sci. Technol. 28, 123-191. doi:10.1080/10643389891254197

Bayani Cardenas, M., Wilson, J.L., 2006. The influence of ambient groundwater discharge on exchange zones induced by current-bedform interactions. J. Hydrol. 331, 103-109. doi:10.1016/j.jhydrol.2006.05.012

Bear, J., 1975. Dynamics of Fluids in Porous Media, Soil Science. Dover Publications. doi:10.1097/00010694-197508000-00022

Bradford, S.A., Simunek, J., Bettahar, M., van Genuchten, M.T., Yates, S.R., 2003. Modeling Colloid Attachment, Straining, and Exclusion in Saturated Porous Media. Environ. Sci. Technol. 37, 2242-2250. doi:10.1021/es025899u

Cardenas, M.B., 2006. Dynamics of fluids, heat and solutes along sediment-water 
interfaces: a multiphysics modeling study. Thesis. doi:10.1126/science.25.629.109

Cardenas, M.B., Wilson, J.L., 2007a. Dunes, turbulent eddies, and interfacial exchange with permeable sediments. Water Resour. Res. 43, 199-212. doi:10.1029/2006WR005787

Cardenas, M.B., Wilson, J.L., 2007b. Hydrodynamics of coupled flow above and below a sediment-water interface with triangular bedforms. Adv. Water Resour. 30, 301-313. doi:10.1016/j.advwatres.2006.06.009

Chen, C., Lau, B.L.T., Gaillard, J.F., Packman, A.I., 2009. Temporal evolution of pore geometry, fluid flow, and solute transport resulting from colloid deposition. Water Resour. Res. 45, 136-148. doi:10.1029/2008WR007252

Chen, C., Packman, A.I., Gaillard, J.-F., 2008. Pore-scale analysis of permeability reduction resulting from colloid deposition. Geophys. Res. Lett. 35, 199-208. doi:10.1029/2007GL033077

Chen, C., Packman, A.I., Zhang, D., Gaillard, J.F., 2010. A multi - scale investigation of interfacial transport, pore fluid flow, and fine particle deposition in a sediment bed 46, 386-398. doi:10.1029/2009WR009018

Drummond, J.D., Davies-Colley, R.J., Stott, R., Sukias, J.P., Nagels, J.W., Sharp, A., Packman, A.I., 2014. Retention and remobilization dynamics of fine particles and microorganisms in pastoral streams. Water Res. 66, 459-472.

doi:10.1016/J.WATRES.2014.08.025 
Elliott, A.H., Brooks, N.H., 1997. Transfer of nonsorbing solutes to a streambed with bed forms: Laboratory experiments. Water Resour. Res. 33, 137-151. doi:10.1029/96WR02783

Elliott, A.H., Brooks, N.H., 1997. Transfer of nonsorbing solutes to a streambed with bed forms: Theory. Water Resour. Res. 33, 123-136. doi:10.1029/96WR02784

Fetzer, J., Holzner, M., Plötze, M., Furrer, G., 2017. Clogging of an Alpine streambed by silt-sized particles - Insights from laboratory and field experiments. Water Res. 126, 60-69. doi:10.1016/J.WATRES.2017.09.015

Findlay, S., 1995. Importance of surface-subsurface The hyporheic zone exchange in stream ecosystems : Limnol. Oceanogr. 40, 159-164. doi:10.4319/lo.1995.40.1.0159

Fox, A., Packman, A.I., Boano, F., Phillips, C.B., Arnon, S., 2018. Interactions Between Suspended Kaolinite Deposition and Hyporheic Exchange Flux Under Losing and Gaining Flow Conditions. Geophys. Res. Lett. 45, 4077-4085. doi:10.1029/2018GL077951

Graton, L.C., Fraser, H.J., 1935. Systematic Packing of Spheres: With Particular Relation to Porosity and Permeability. J. Geol. 43, 785-909.

Harvey, J.W., Drummond, J.D., Martin, R.L., McPhillips, L.E., Packman, a. I., Jerolmack, D.J., Stonedahl, S.H., Aubeneau, a. F., Sawyer, a. H., Larsen, L.G., Tobias, C.R., 2012. Hydrogeomorphology of the hyporheic zone: Stream solute and fine particle interactions with a dynamic streambed. J. Geophys. Res. Biogeosciences 117, 1-20. doi:10.1029/2012JG002043 
Harvey, J.W., Fuller, C.C., 1998. Effect of enhanced manganese oxidation in the hyporheic zone on basin-scale geochemical mass balance. Water Resour. Res. 34, 623-636. doi:10.1029/97WR03606

Hedges, J.I., Clark, W.A., Quay, P.D., Richey, J.E., Devol, A.H., Santos, M., 1986. Compositions and fluxes of particulate organic material in the Amazon River1. Limnol. Oceanogr. 31, 717-738. doi:10.4319/1o.1986.31.4.0717

Hunter, R.J., 1986. Foundations of colloid science. Oxford University Press.

Jin, G., Tang, H., Gibbes, B., Li, L., Barry, D.A., 2010. Transport of nonsorbing solutes in a streambed with periodic bedforms. Adv. Water Resour. 33, 1402-1416. doi:http://dx.doi.org/10.1016/j.advwatres.2010.09.003

Jin, G., Zhang, Z., Tang, H., Xiaoquan, Y., Li, L., Barry, D.A., 2019. Colloid transport and distribution in the hyporheic zone. Hydrol. Process. 33, 932-944. doi:10.1002/hyp.13375

Karathanasis, A.D., 2000. Colloid-mediated transport of $\mathrm{Pb}$ through soil porous media. Int. J. Environ. Stud. 57, 579-596. doi:10.1080/00207230008711298

Karathanasis, A.D., 1999. Subsurface migration of copper and zinc mediated by soil colloids. Soil Sci. Soc. Am. J. 63, 830-838. doi:10.2136/sssaj1999.634830x

Karwan, D.L., Saiers, J.E., 2012. Hyporheic exchange and streambed filtration of suspended particles. Water Resour. Res. 48, 1519-1531.

doi:10.1029/2011WR011173 
Krause, S., Hannah, D.M., Fleckenstein, J.H., 2009. Hyporheic hydrology: interactions at the groundwater-surface water interface. Hydrol. Process. 23, 2103-2107. doi:10.1002/hyp.7366

Liu, D., Johnson, P.R., Elimelech, M., 1995. Colloid deposition dynamics in flowthrough porous media: role of electrolyte concentration. Environ. Sci. Technol. 29, 2963-2973. doi:10.1021/es00012a012

Malcolm, I.A., Soulsby, C., Youngson, A.F., 2002. Thermal regime in the hyporheic zone of two contrasting salmonid spawning streams: Ecological and hydrological implications. Fish. Manag. Ecol. 9, 1-10. doi:10.1046/j.1365-2400.2002.00276.x

Mays, D.C., Hunt, J.R., 2007. Hydrodynamic and Chemical Factors in Clogging by Montmorillonite in Porous Media. Environ. Sci. Technol. 41, 5666-5671. doi:10.1021/es062009s

Mays, D.C., Hunt, J.R., 2005. Hydrodynamic Aspects of Particle Clogging in Porous Media. Environ. Sci. Technol. 39, 577-584. doi:10.1021/es049367k

McDowell-Boyer, L.M., Hunt, J.R., Sitar, N., 1986. Particle transport through porous media. Water Resour. Res. 22, 1901-1921. doi:10.1029/WR022i013p01901

Mermillod-Blondin, F., Mauclaire, L., Montuelle, B., 2005. Use of slow filtration columns to assess oxygen respiration, consumption of dissolved organic carbon, nitrogen transformations, and microbial parameters in hyporheic sediments. Water Res. 39, 1687-1698. doi:10.1016/j.watres.2005.02.003 
O’Melia, C.R., Ali, W., 1978. The Role of Retained Particles in Deep-Bed Filtration, Progress in Water Technology. doi:10.1016/B978-0-08-022939-3.50019-2

Packman, A.I., Brooks, N.H., 1995. Colloidal Particle Exchange Between Stream and Stream Bed in a Laboratory Flume. Mar. Freshw. Res. 46, 233-236. doi:10.1071/mf9950233

Packman, A.I., Brooks, N.H., Morgan, J.J., 2000a. A physicochemical model for colloid exchange between a stream and a sand streambed with bed forms. Water Resour. Res. 36, 2351-2361. doi:10.1029/2000WR900059

Packman, A.I., Brooks, N.H., Morgan, J.J., 2000b. Kaolinite exchange between a stream and streambed: Laboratory experiments and validation of a colloid transport model. Water Resour. Res. 36, 2363-2372. doi:10.1029/2000WR900058

Packman, A.I., MacKay, J.S., 2003. Interplay of stream-subsurface exchange, clay particle deposition, and streambed evolution. Water Resour. Res. 39, 122-137. doi:10.1029/2002WR001432

Pholkern, K., Srisuk, K., Grischek, T., Soares, M., Schäfer, S., Archwichai, L., Saraphirom, P., Pavelic, P., Wirojanagud, W., 2015. Riverbed clogging experiments at potential river bank filtration sites along the Ping River, Chiang Mai, Thailand. Environ. Earth Sci. 73, 7699-7709. doi:10.1007/s12665-015-4160-x

Pimentel, D., Harvey, C., Resosudarmo, P., Sinclair, K., Kurz, D., McNair, M., Crist, S., Shpritz, L., Fitton, L., Saffouri, R., Blair, R., 1995. Environmental and Economic Costs of Soil Erosion and Conservation Benefits. Science (80-. ). 267, 1117-1123. 
Pryshlak, T.T., Sawyer, A.H., Stonedahl, S.H., Soltanian, M.R., 2015. Multiscale hyporheic exchange through strongly heterogeneous sediments. Water Resour. Res. doi:10.1002/2015WR017293

Rajagopalan, R., Tien, C., 1976. Trajectory analysis of deep-bed filtration with the sphere-in-cell porous media model. AIChE J. 22, 523-533.

doi:10.1002/aic.690220316

Reddi, L.N., Xiao, M., Hajra, M.G., Lee, I.M., 2005. Physical clogging of soil filters under constant flow rate versus constant head. Can. Geotech. J. 42, 804-811. doi:10.1139/t05-018

Rehg, K.J., Packman, A.I., Ren, J., 2005. Effects of suspended sediment characteristics and bed sediment transport on streambed clogging. Hydrol. Process. 19, 413-427. doi:10.1002/hyp.5540

Ren, J., Packman, A.I., 2005. Coupled stream-subsurface exchange of colloidal hematite and dissolved zinc, copper, and phosphate. Environ. Sci. Technol. 39, 6387-6394. doi:10.1021/es050168q

Ren, J., Packman, A.I., 2004. Modeling of simultaneous exchange of colloids and sorbing contaminants between streams and streambeds. Environ. Sci. Technol. 38, 29012911. doi:10.1021/es0348521

Ren, J., Packman, A.I., Welty, C., 2001. Analysis of an observed relationship between colloid collision efficiency and mean collector grain size. Colloids Surfaces A Physicochem. Eng. Asp. 191, 133-144. doi:10.1016/S0927-7757(01)00770-1 
Ren, J., Packman, A.I., Welty, C., 2000. Correlation of colloid collision efficiency with hydraulic conductivity of silica sands. Water Resour Res 36, 2493-2500. doi:10.1029/2000WR900163

Ryan, J.N., Elimelech, M., 1996. Colloid mobilization and transport in groundwater. Colloids Surfaces A Physicochem. Eng. Asp. 107, 1-56. doi:10.1016/09277757(95)03384-X

The Professional Standards Compilation Group of People's Republic of China, 1999. Chinese National Standard. Standard for soil test method (GB/T50123-1999). China Planning Press, Beijing.

Thibodeaux, L.J., Boyle, J.D., 1987. Bedform-generated convective transport in bottom sediment. Nature 325, 341-343. doi:10.1038/325341a0

Tonina, D., de Barros, F.P.J., Marzadri, A., Bellin, A., 2016. Does streambed heterogeneity matter for hyporheic residence time distribution in sand-bedded streams? Adv. Water Resour. doi:10.1016/j.advwatres.2016.07.009

Tosco, T., Sethi, R., 2010. Transport of non-newtonian suspensions of highly concentrated micro- and nanoscale iron particles in porous media: A modeling approach. Environ. Sci. Technol. 44, 9062-9068. doi:10.1021/es100868n

Wolman, M.G., 1967. A Cycle of Sedimentation and Erosion in Urban River Channels. Geogr. Ann. Ser. A, Phys. Geogr. 49, 385-395. doi:10.2307/520904

Xu, P., Yu, B., 2008. Developing a new form of permeability and Kozeny-Carman 
constant for homogeneous porous media by means of fractal geometry. Adv. Water Resour. 31, 74-81. doi:10.1016/j.advwatres.2007.06.003

Yao, K.M., Habibian, M.T., O’Melia, C.R., 1971. Water and waste water filtration. Concepts and applications. Environ. Sci. Technol. 5, 1105-1112. doi:10.1021/es60058a005

Zheng, X., Shan, B., Chen, L., Sun, Y., Zhang, S., 2014. Attachment-detachment dynamics of suspended particle in porous media: Experiment and modeling. J. Hydrol. 511, 199-204. doi:http://dx.doi.org/10.1016/j.jhydrol.2014.01.039 
Table 1 Parameter values in the field experiment.

\begin{tabular}{ll}
\hline Parameter & Value \\
\hline Bedform length $(L)$ & $1.4 \mathrm{~m}$ \\
Bedform height $\left(H_{b}\right)$ & $14.7 \mathrm{~cm}$ \\
Stoss length $\left(L_{c}\right)$ & $98 \mathrm{~cm}$ \\
Streambed depth $\left(d_{b}\right)$ & $10 \mathrm{~cm}$ \\
Hydraulic conductivity $(K)$ & $8.84 \times 10^{-4} \mathrm{~m} / \mathrm{s}$ \\
Bulk porosity $(\theta)$ & 0.33 \\
Mean diameter of streambed sediments $(d)$ & $3 \times 10^{-4} \mathrm{~m}$ \\
Median fine particle size in overlying water $\left(d_{50}\right)$ & $7.39 \sim 10.84 \mu \mathrm{m}$ \\
Median fine particle size in sand dune $\left(d_{50}\right)$ & $9.66 \mu \mathrm{m}$ \\
\hline
\end{tabular}

Table 2 Bulk density measured at sample locations.

\begin{tabular}{llllll}
\hline Type & $\begin{array}{l}\text { Location and } \\
\text { Name } \\
(\text { shallow })\end{array}$ & $\begin{array}{l}\text { Bulk } \\
\text { Density } \\
\left(\mathrm{g} / \mathrm{cm}^{3}\right)\end{array}$ & $\begin{array}{l}\text { Location and } \\
\text { Name }^{\mathrm{a}}(\mathrm{deep})\end{array}$ & $\begin{array}{l}\text { Bulk } \\
\text { Density } \\
\left(\mathrm{g} / \mathrm{cm}^{3}\right)\end{array}$ & $\begin{array}{l}\text { Increase } \\
\text { Mass Rate } \\
(\%)\end{array}$ \\
\hline Field & A1 & 1.83 & A1' & 1.72 & $6.40^{\mathrm{b}}$ \\
Experiment & $\mathrm{A} 2$ & 1.81 & A2' & 1.69 & 7.10 \\
& A3 & 1.81 & A3' & 1.67 & 8.38 \\
\hline
\end{tabular}

Note: a Two layers were sampled at the middle of sand dune. Three samples were extracted at each layer, the location of these three samples is vertical to flow direction. The quotes suggest the sample was extracted bellow the corresponding numbered sample. For example, A1, A2 and A3 was in the same layer. A1' was extracted bellow A1. b Increase mass rate is calculated as $\left(\rho_{A 1}-\rho_{A 1^{\prime}}\right) / \rho_{A 1^{\prime}} *$ $100 \%$ 
Table 3 Values of model parameters used in generalized numerical simulations.

\begin{tabular}{|c|c|}
\hline Parameter & Value \\
\hline Bedform length $(L)$ & $1 \mathrm{~m}$ \\
\hline Bedform height $\left(H_{b}\right)$ & $5 \mathrm{~cm}$ \\
\hline Stoss length $\left(L_{c}\right)$ & $90 \mathrm{~cm}$ \\
\hline Streambed depth $\left(d_{b}\right)$ & $1 \mathrm{~m}$ \\
\hline Hydraulic conductivity $(K)$ & $8.84 \times 10^{-4} \mathrm{~m} / \mathrm{s}$ \\
\hline Bulk porosity $(\theta)$ & 0.33 \\
\hline Water density $(\rho)$ & $1000 \mathrm{~kg} / \mathrm{m}^{3}$ \\
\hline Water dynamic viscosity $(\mu)$ & $0.001 \mathrm{~Pa} \mathrm{~s}$ \\
\hline Longitudinal dispersivity $\left(\alpha_{L}\right)$ & $0.01 \mathrm{~m}$ \\
\hline Transverse dispersivity $\left(\alpha_{T}\right)$ & $0.001 \mathrm{~m}$ \\
\hline Effective diffusion coefficient $\left(D_{e}\right)$ & $10^{-9} \mathrm{~m}^{2} / \mathrm{s}$ \\
\hline Initial colloid concentration in overlying water $(C=$ & $0.5 \mathrm{~kg} / \mathrm{m}^{3}$ (base case), $0.5 \sim 16$ \\
\hline$\left.C_{0}\right)$ & $\mathrm{kg} / \mathrm{m}^{3}$ (for the parametric study) \\
\hline Pressure difference at bed surface $\left(h_{m}\right)$ & $\begin{array}{l}4.75 \times 10^{-4} \mathrm{~m} \text { (base case), } \\
1.11 \sim 6.44 \times 10^{-4} \mathrm{~m} \text { (for the } \\
\text { parametric study) }\end{array}$ \\
\hline Mean diameter of streambed Sediments $(d)$ & $3 \times 10^{-4} \mathrm{~m}$ \\
\hline Fine particle size $(\mu \mathrm{m})$ & $\begin{array}{l}1 \mu \mathrm{m} \text { (base case), } 1 \sim 10 \mu \mathrm{m} \text { (for } \\
\text { the parametric study) }\end{array}$ \\
\hline Particle collision efficiency coefficient $\alpha$ & $\begin{array}{l}0.04 \text { (base base), } 0.04 \sim 0.6 \text { (for } \\
\text { the parametric study) }\end{array}$ \\
\hline
\end{tabular}




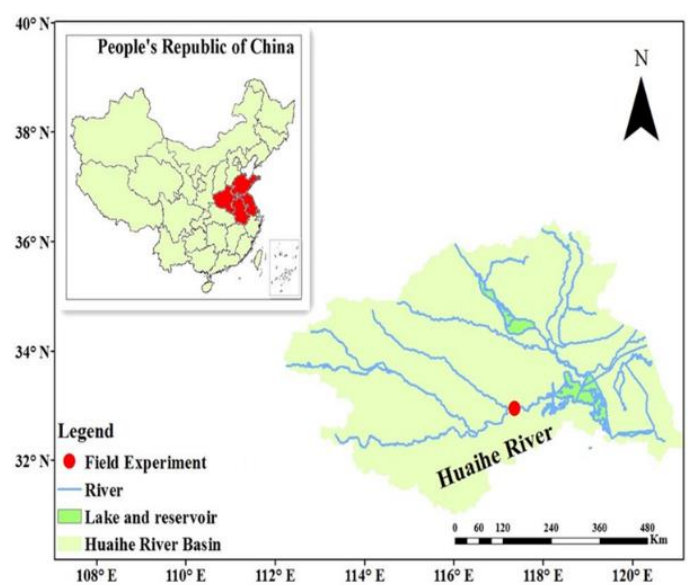

(a)

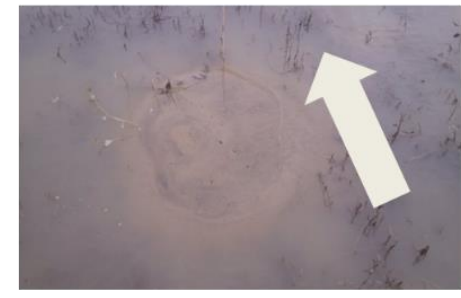

(b)

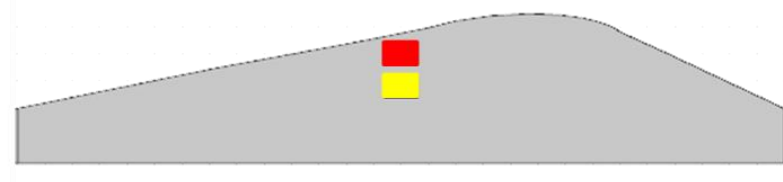

(c)
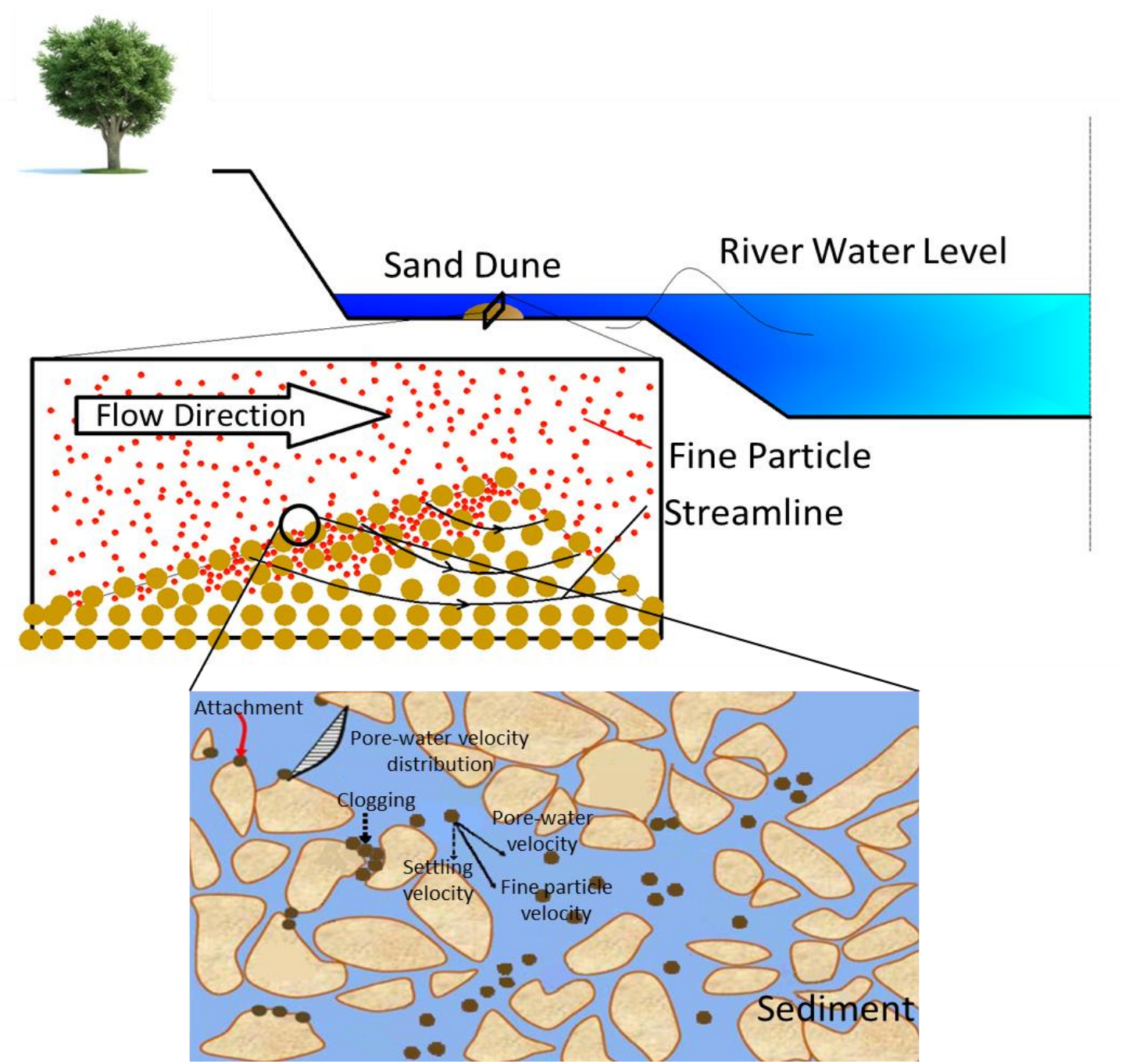

(d)

Figure 1. (a) Location of the field experiment on the Huaihe River. (b) At the field site, a 1.4-m long and 0.15-m high sand dune was set up on the floodplain to simulate bedformriver flow interactions and the resulting hyporheic flow and fine particle transport. The arrow indicates the river flow direction during the experiment over a flood event. (c) 
Illustration of setup of the field experiment. The red and yellow boxes show shallow and deep sampling locations, respectively. The sampling region was $61.6-\mathrm{mm}$ long and $40.0-$ $\mathrm{mm}$ high. (d) Schematic diagram of the experiment set-up, showing trapping of fine particles from the overlying water and the underlying.

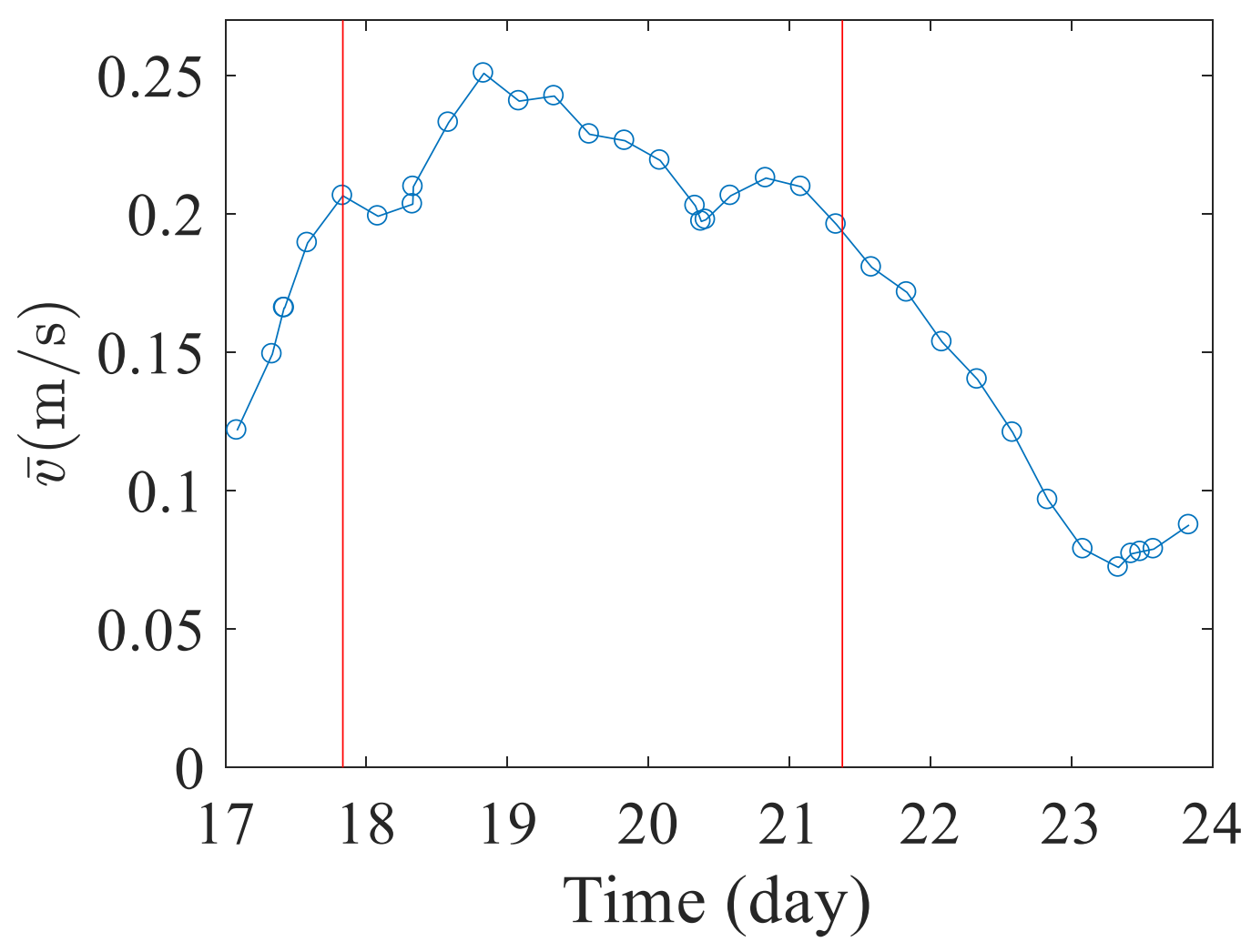



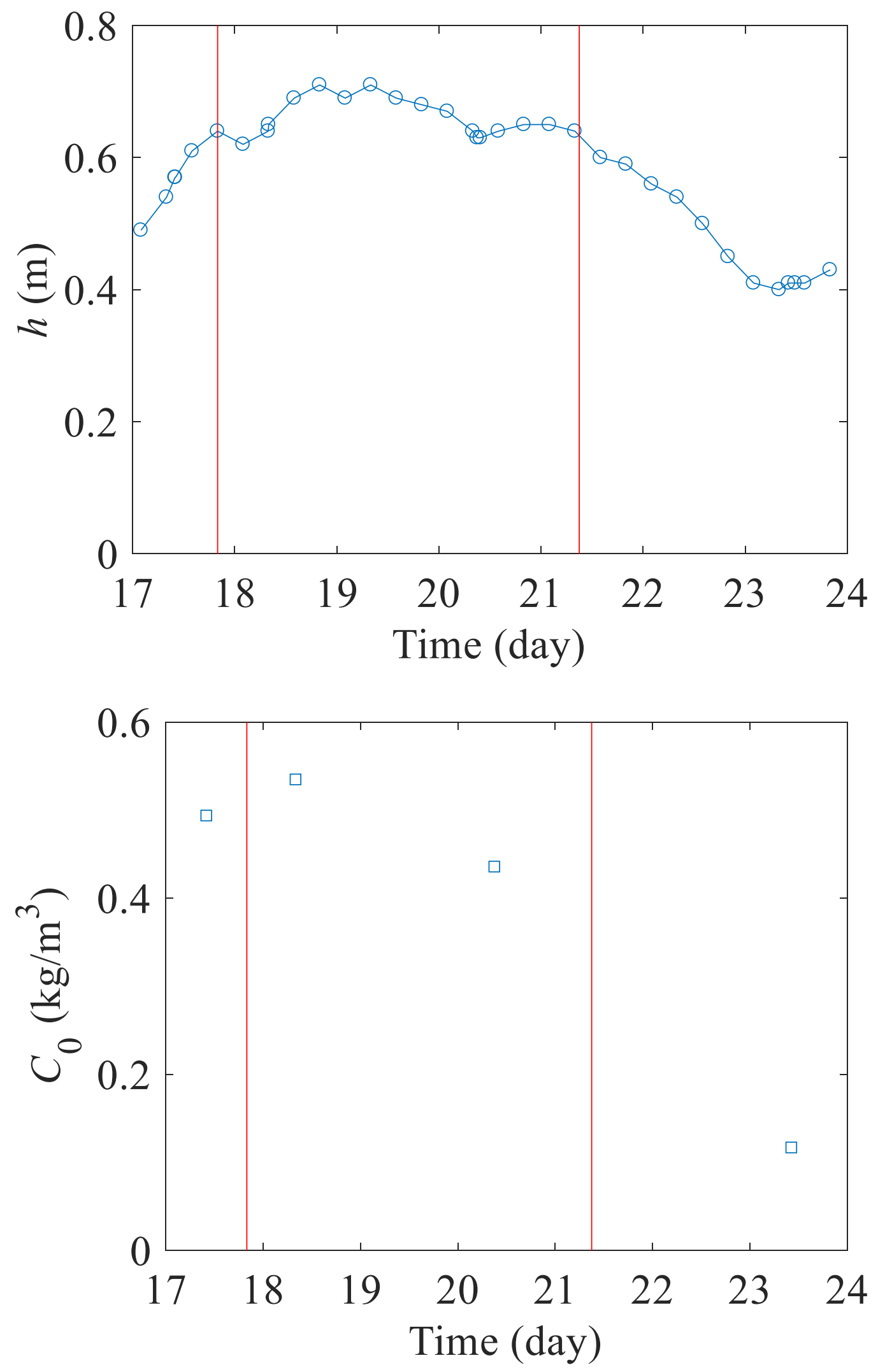
Figure 2. Mean velocity, water depth and particle concentration over the floodplain during the field experiment. The red lines show the study period (from July 17, $20 \mathrm{pm}$ to July 17, $9 \mathrm{am}$ ) of the field experiment. The experiment was conducted during July 2015 (dates shown on the horizontal axis).

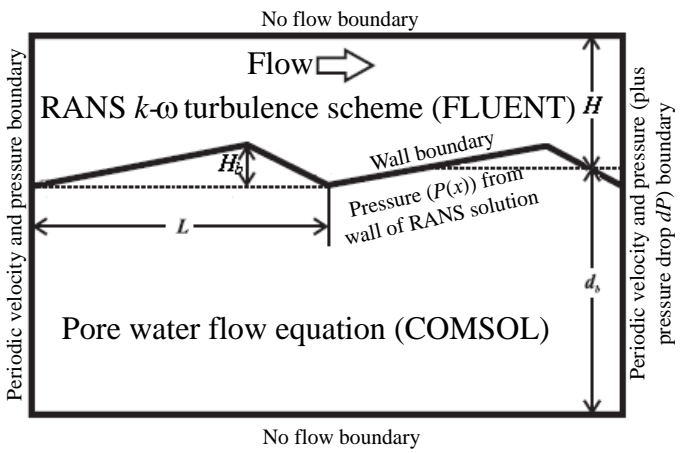

(a)

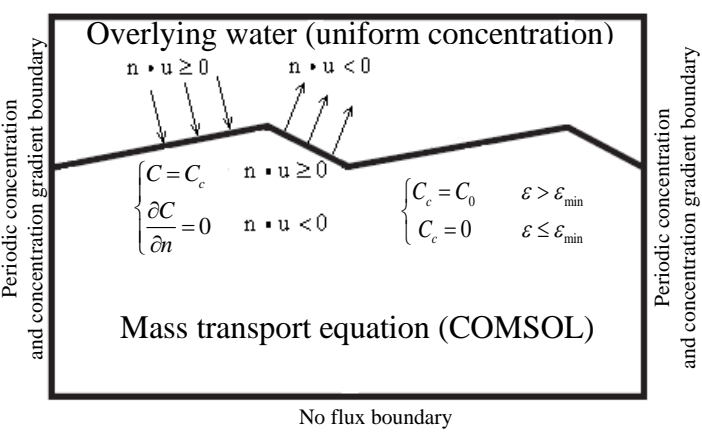

(b)

Figure 3. Schematic diagrams of the simulation domain and boundaries. (a) For water flow: $L, H, H_{b}$ and $d_{b}$ are bedform length, average water depth of overlying water, bedform height and average streambed depth, respectively. (b) For fine particle transport, $\mathbf{n}, \mathbf{u}$ and $C_{\mathrm{c}}$ are the unit vector normal to the interface (pointing inward), pore-water flow velocity vector and the fine particle influx concentration along the SWI (sediment water interface), respectively.

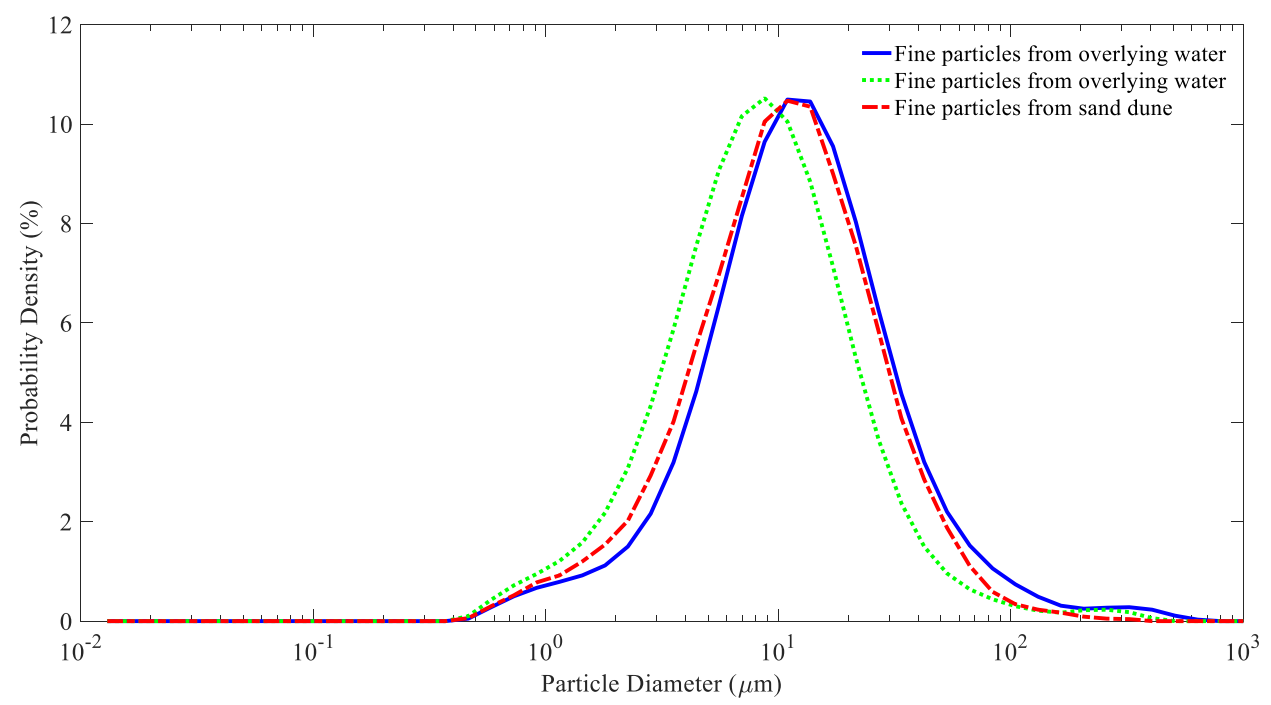

Figure 4. Probability density of the particle size distribution for suspended particles sampled from the river water (blue and green lines, green line was measured earlier than blue line) and sieved fine particles from sediment samples collected from the sand dune near the dune surface after the experiment (red line). 
(a)

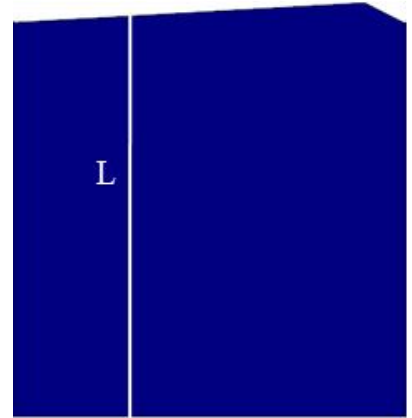

(1)

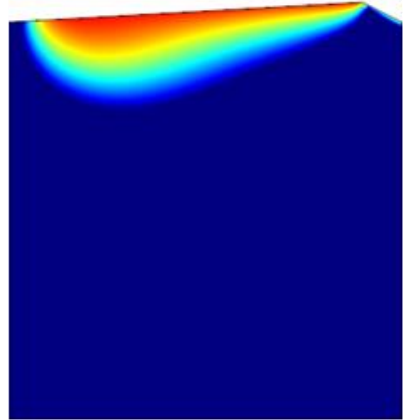

(2)

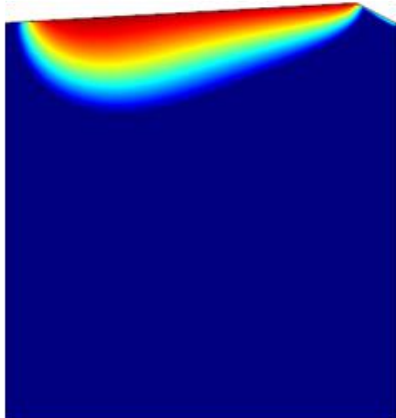

(3)

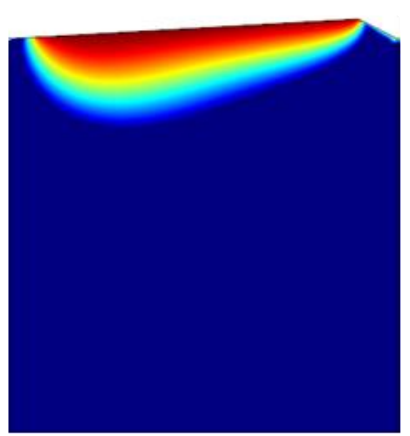

(4)

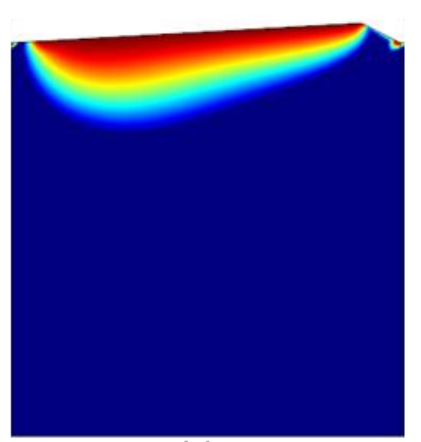

(5)

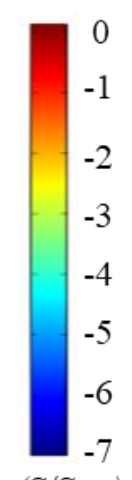

$\ln \left(S / S_{\max }\right)$

(b)

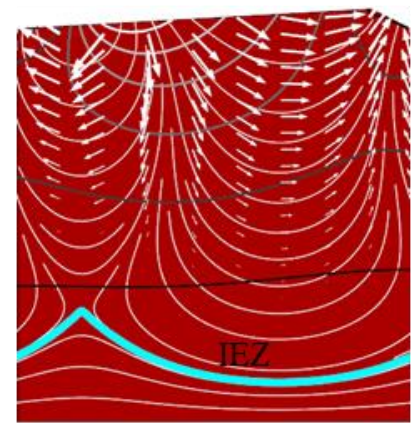

(1)

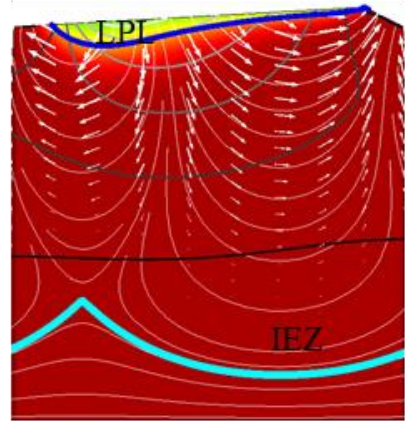

(2)

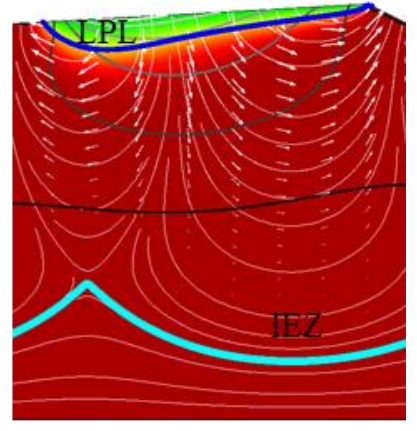

(3)

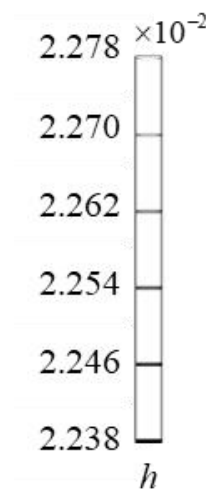

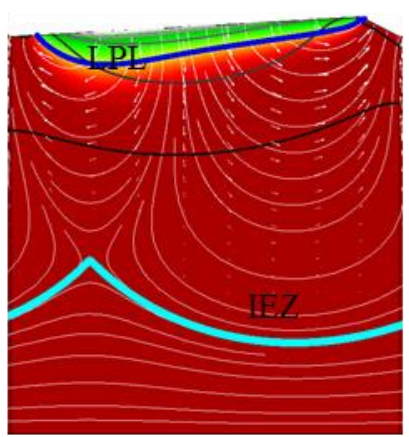

(4)

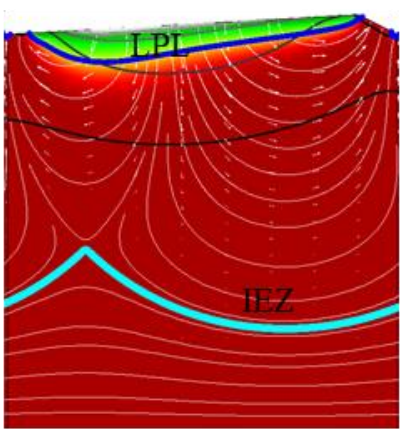

(5)

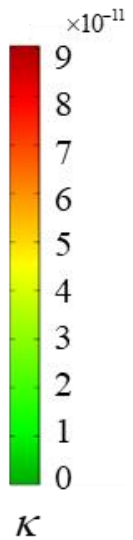

$\kappa$

Figure 5. Simulated spatial-temporal variations of (a) trapped particle concentrations $\ln \left(S / S_{\max }\right)$, and (b) permeability $\left(\kappa, \mathrm{m}^{2}\right)$ and flow patterns. Arrows show the flow velocity vectors, white lines show flow pathlines and the thick cyan line indicates the 
hydraulic divide separating the IEZ (interfacial exchange zone) and regional flow zone. Green area surrounded by blue line was the low permeability layer (LPL). The grey lines are contours of hydrodynamic pressure heads $h(\mathrm{~m})$. Sub-panels are numbered according to the elapsed time: (1) $t=0$ (h), (2) $t=7,518$ (h), (3) $t=17,182$ (h), (4) $t=27,921$ (h) and (5) $t=92,354(\mathrm{~h})$. The average porosities of the sediment-water interface at these times are $0.33,0.32,0.31,0.30$ and 0.19 , respectively. The blue lines show the contours of fifty percent of the initial permeability. The vertical line $\mathrm{L}$ indicates the location where the vertical concentration profile of trapped particles is shown in Fig. 6.

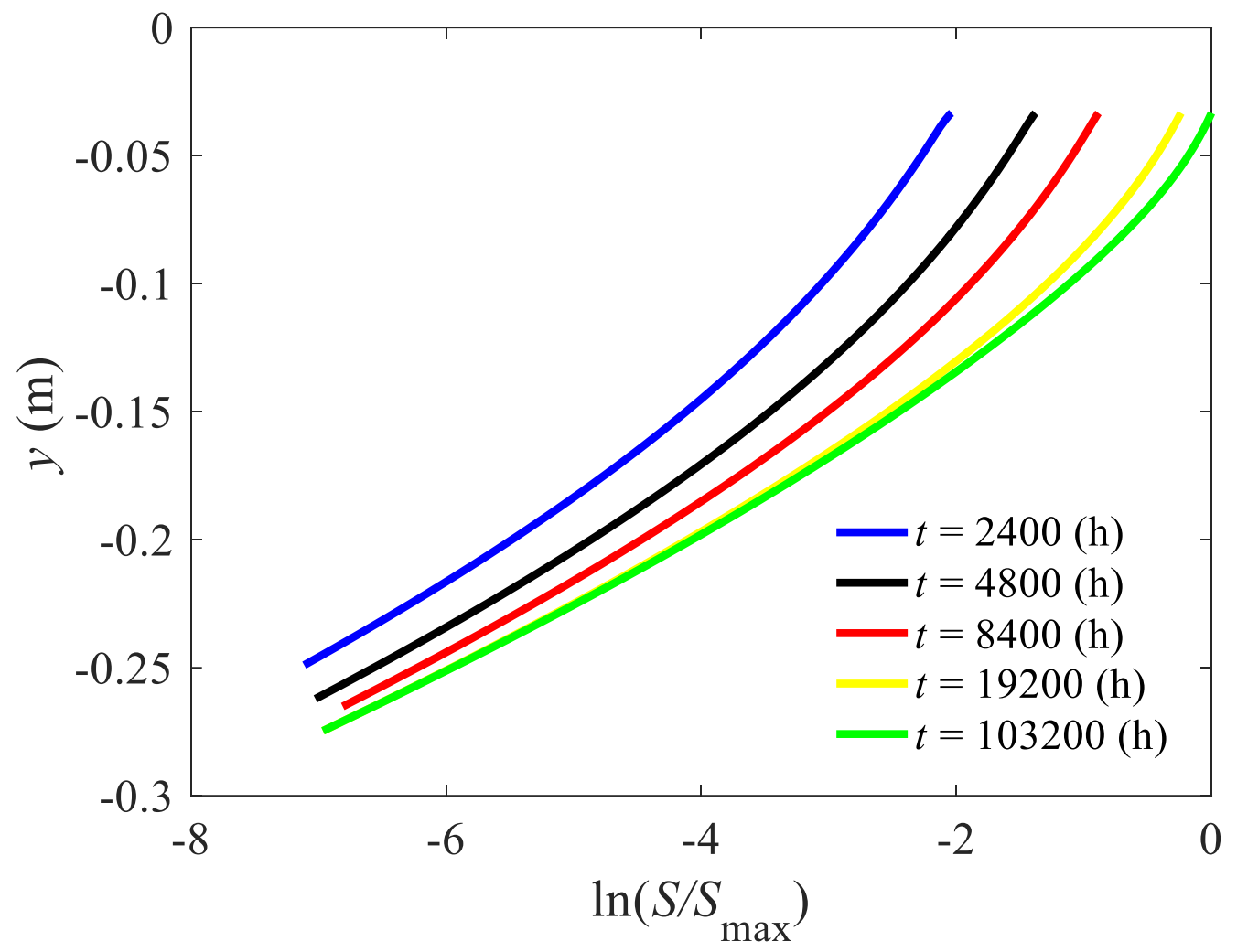

Figure 6. Vertical profiles of $\ln \left(S / S_{\max }\right)$ at the location L shown in Fig. 5. Particle diameter is $1 \mu \mathrm{m}$ and sediment collision efficiency is 0.04 

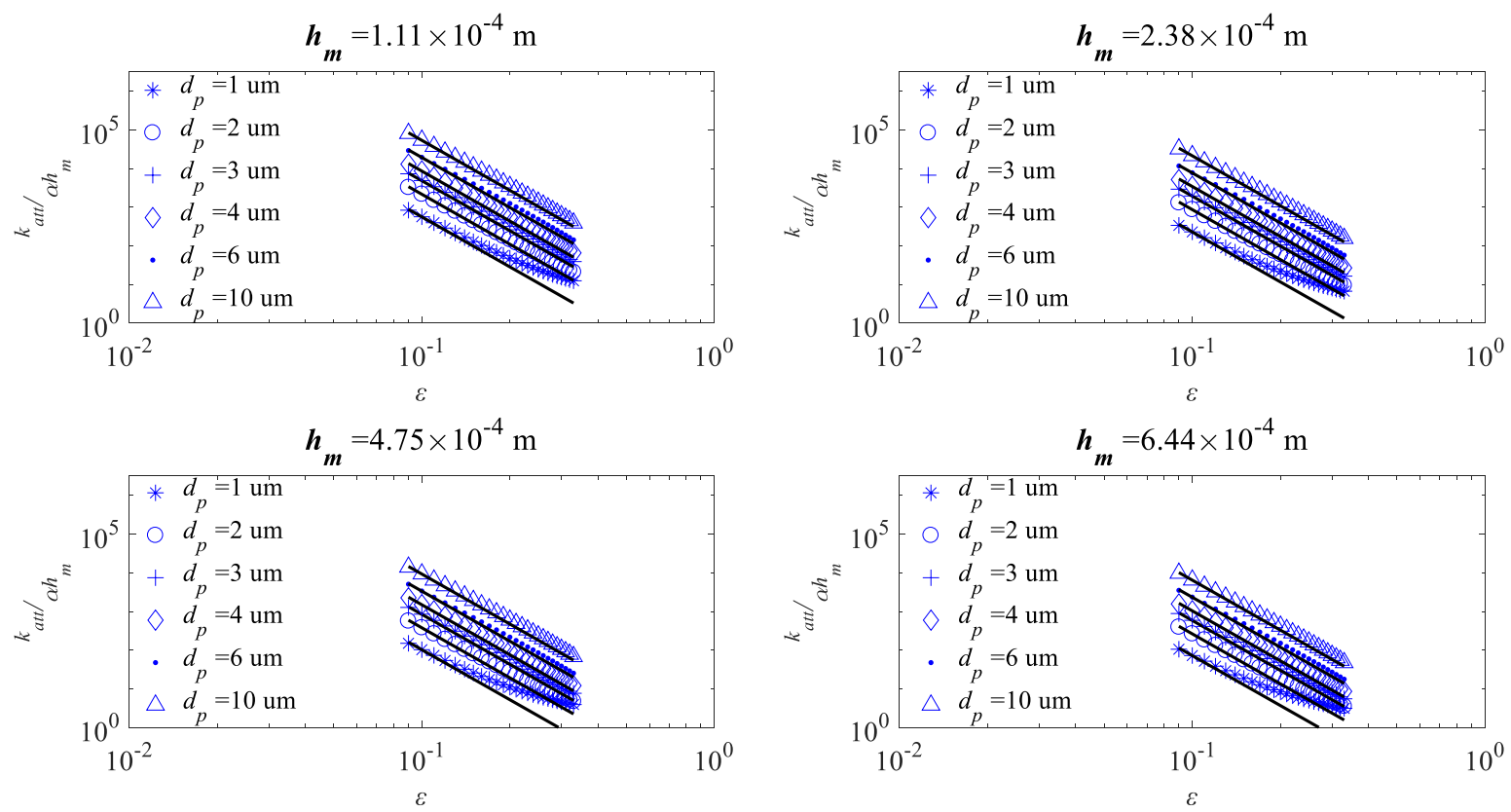

Figure 7. Relationships between porosity $\varepsilon$ and $k_{\text {att }} / \alpha h_{m}$ shown in log-log coordinates for different fine particle diameters and different pressure difference. Based on the fitting, it was found that $k \cong 4.43 \times 10^{6}$ and $n \cong 4.3$ in Eq. $13 \mathrm{~b}$. The lines represent the values used in the analytical model, while the symbols represent the values used in the numerical model. 


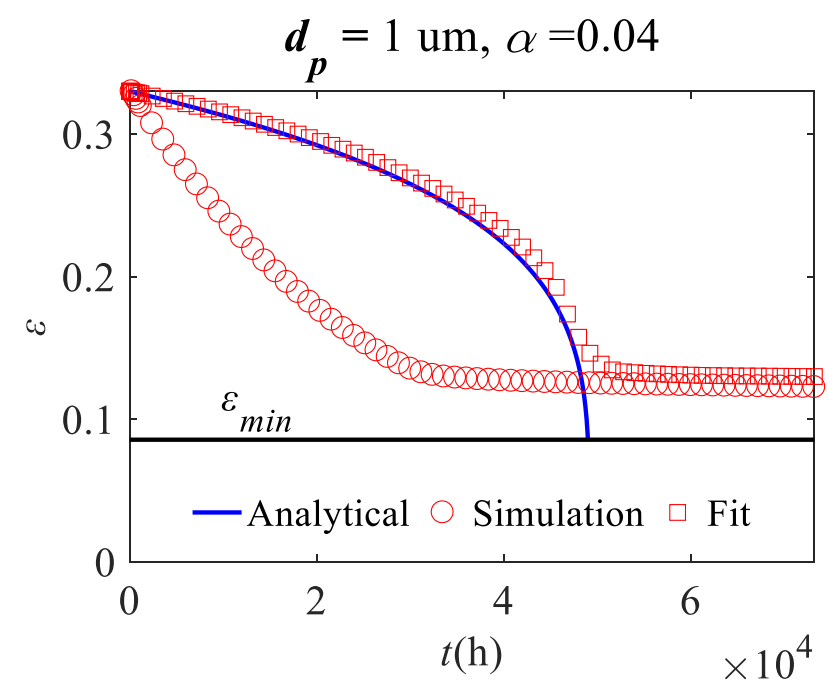

Figure 9. Comparison between $\varepsilon^{*}$ (predicted by the simplified analytical model shown as the blue line) and $\varepsilon_{a}$ (simulated by the numerical model, with $k_{\text {att }}$ based on Eqs. 5 and 6, shown as red circles; and $k_{\text {att }}$ based on the fitted power law relationship, Eq. $13 \mathrm{~b}$, as adopted in the analytical model and solution, shown as red squares) for the base case $\left(d_{\mathrm{p}}=1 \mu \mathrm{m}, \alpha=0.04\right)$.
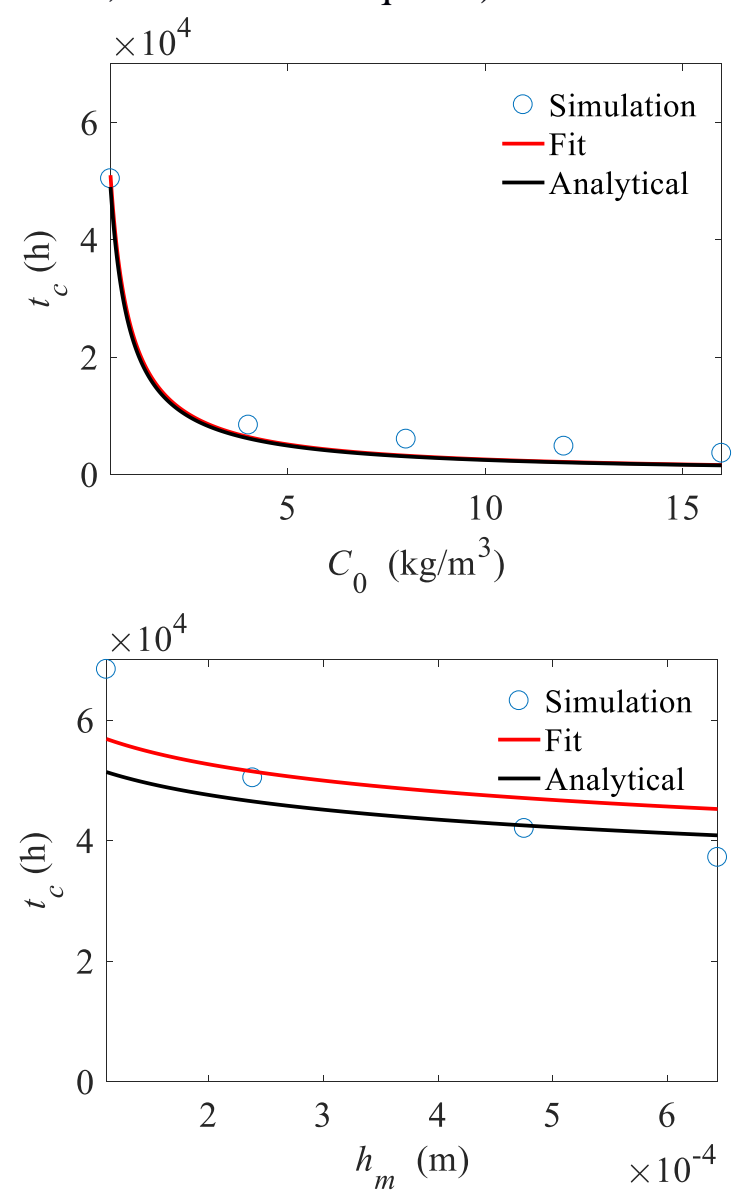

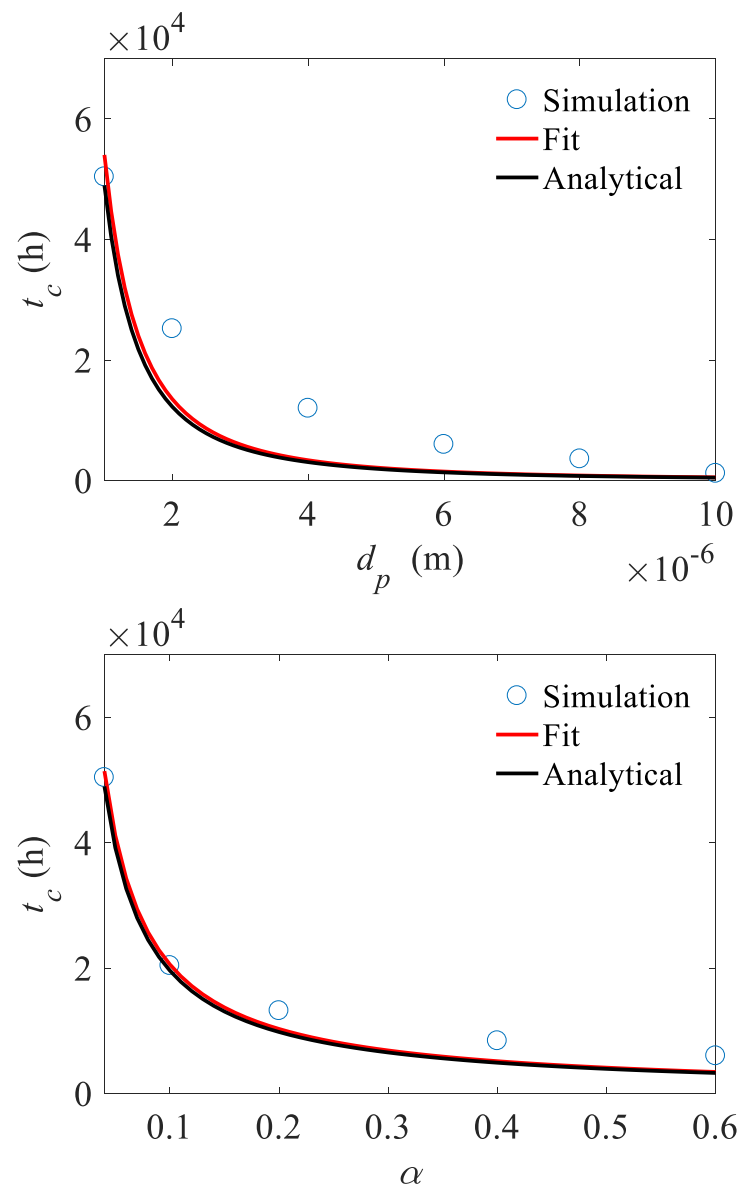

Figure 10. Predicted and simulated $t_{c}$ under the influence of $C_{0}, h_{m}, d_{p}$ and $\alpha$.

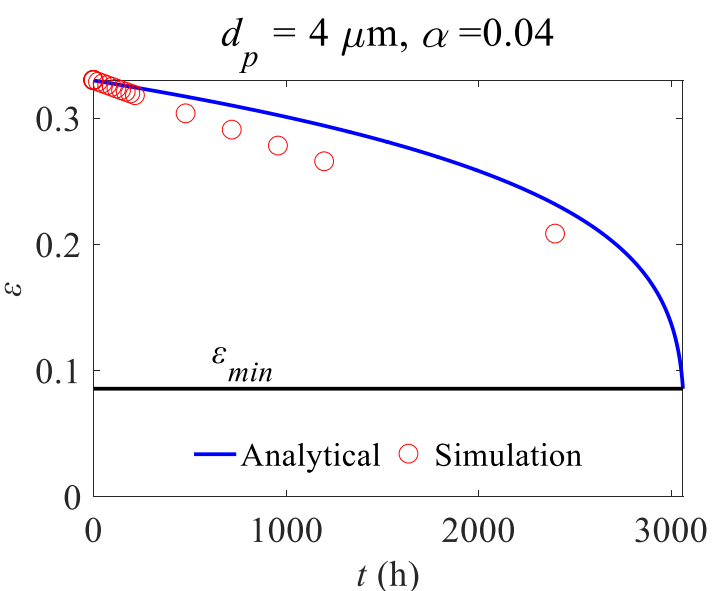




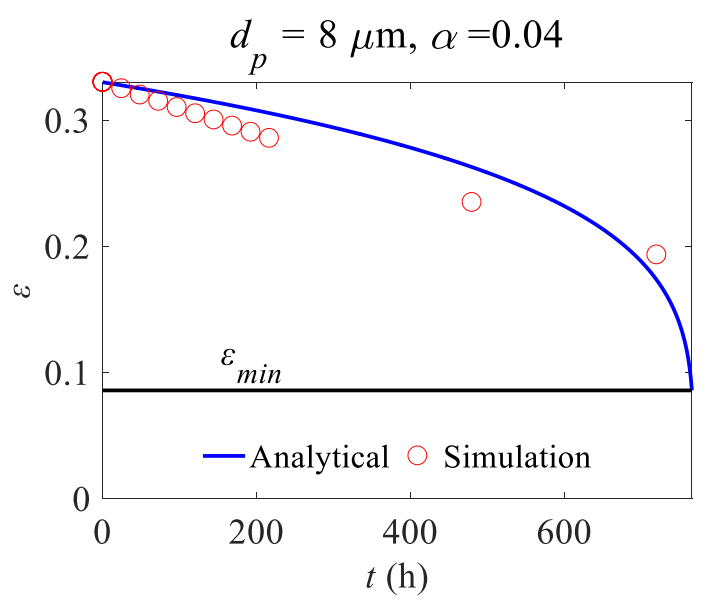

Figure 11. Comparison between $\varepsilon^{*}$ and $\varepsilon_{a}$ under different particle sizes. The Blue line shows the value of $\varepsilon^{*}$ based on analytical value, and the red dot shows the value of $\varepsilon_{a}$ based on simulation. 